\title{
Placental peptides as markers of gestational disease
}

\author{
Nigel M. Page, C. Fred Kemp, David J. Butlin and Philip J. Lowry \\ School of Animal and Microbial Sciences, The University of Reading, Reading, RG6 6AJ, UK
}

\begin{abstract}
The human placenta produces a wide range of important peptides, of which an intricate balance is required throughout pregnancy. In a gestational disease, this balance may be disturbed and the identification of such changes may be used to detect a particular pathology or to ascertain its severity. This review considers the role and association of various placental peptide markers associated with the major gestational diseases including intrauterine growth retardation, pre-term labour, pre-eclampsia, chromosomal disorders, gestational diabetes and trophoblastic disease. Potential markers that may prove more reliable and specific in their diagnostic value and that may be used for identifying patients at risk are also discussed. The importance of the new fields of genomics and proteomics in the future discovery of new peptide markers is illustrated.
\end{abstract}

\begin{abstract}
The placenta is a temporary structure unique to pregnancy functioning to sustain and protect the fetus until birth. The placenta serves as an endocrine organ producing a wide range of important signals, including many peptide hormones. Many of these peptides enter the maternal and fetal circulation and have diverse effects on the metabolic, immune and cardiovascular systems. An intricate balance of these signals is required throughout pregnancy and, in a gestational disease, this balance may be disturbed. The identification of such changes in the balance of signals may be used to detect a particular type of pathology or to ascertain its severity. Peptides possess characteristics that make them invaluable candidates for markers of gestational disease. For example, they are often secreted from the cell, increasing their chance of entering the maternal or fetal circulation, where they can be detected easily (Fig. 1). In addition, the number of known peptides greatly exceeds the number of non-peptide messages, and therefore provides a wider choice of potential markers.
\end{abstract}

\section{Gestational diseases}

In this review, the role and association of a selection of placental peptides with regard to the major gestational diseases are considered and the discussion is confined to some of the more prominent and promising candidates.

\section{Intrauterine growth restriction}

Intrauterine growth restriction (IUGR) is defined as a predicted fetal weight for gestational age that is under the tenth percentile or $<2.5 \mathrm{~kg}$. IUGR has been linked to significantly increased fetal morbidity and mortality (McCormick, 1985), with the most common causes stated as chronic

Email: sasnpage@reading.ac.uk hypertension, pre-eclampsia, smoking, alcohol, stress and intrauterine infections such as cytomegalovirus and rubella. These conditions are commonly cited as causing an inadequate maternal-fetal circulation.

\section{Growth factors}

Fetal growth and development are closely regulated by the paracrine and autocrine actions of various growth factors such as the insulin-like growth factors (IGF), fibroblast growth factors (FGF), epidermal growth factors (EGF), transforming growth factors (TGF) and platelet derived growth factors (PDGF). Therefore, attention has been drawn to the study of these growth factors in IUGR. The availability of these growth factors is controlled not only by gene expression, but also by proteolytic release. For example, some FGFs are stored within basement membranes and are inaccessible to target tissues without liberation by proteolysis (Herbert et al., 1990). IGF-I and IGF-II circulate in association with specific binding proteins (IGFBPs), and their bioavailability depends on the proteolysis of the specific IGFBPs.

IGF-I is believed to be the primary hormone influencing fetal growth in later gestation and is essential for placental and fetal development (Hill et al., 1998). The targeted gene deletion of the IGF-I gene in mice is shown to yield homozygotes that have a birth weight about $60 \%$ that of normal (Liu et al., 1993). During pregnancy, IGF-I concentrations parallel the increase in fetal size that occurs with advancing gestation (Bocconi et al., 1998). Thus, it is not surprising that low IGF-I concentrations correlate with infants suspected of IUGR (Lassarre et al., 1991; Ostlund et al., 1997) or that increased concentrations correlate with large-for-gestationalage fetuses (Giudice et al., 1995). There is also evidence to indicate an inverse relationship between increased IGFBP-1 concentrations at delivery and birth size (Wang et al., 1991; Holmes et al., 2000). Subsequently, the increased IGFBP-1 may be responsible for limiting the availability of IGF-I in 


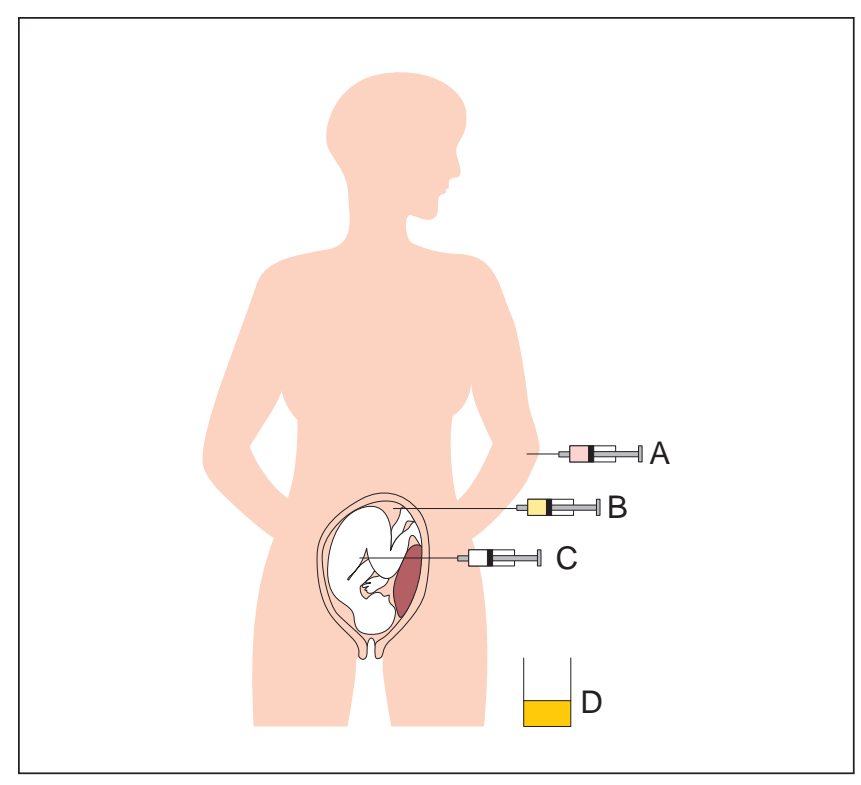

Fig. 1. Procedures used to collect peptides from the mother or fetus during pregnancy. (a) Venous blood sampling (non-invasive); (b) amniocentesis (invasive): (c) cordocentesis (invasive); and (d) urine sampling (non-invasive).

the circulation observed in cases of IUGR. Nevertheless, the observed serum concentrations of IGF-I are not always reflected as differences in the amount of gene expression between normal and IUGR placentas (Abu-Amero et al., 1998). Indeed, increased expression of IGF-I in the placentas of IUGR fetuses has been proposed as a mechanism for restoring normal growth (Dalcik et al., 2001).

Protein production and release are not abnormal in all IUGR placentas but are found to be aberrant only in certain cases (Sorem and Siler-Khodr, 1998), possibly because a variety of other fetal tissues also secrete IGF-I. Leger et al. (1996) suggested that serum IGF-I concentrations are influenced by nutritional factors, leading to a wide range of individual differences in measurements and making IGF-I a potentially poor marker for IUGR.

EGF plays a key role in placental implantation, growth and differentiation and is the second most studied growth factor associated with IUGR. EGF has the advantage that it can be measured directly in urine, in which in normal pregnancies concentrations increase linearly from week 6 to week 20 of gestation, and then decline towards term (Hofmann et al., 1988). No correlation of EGF concentrations was observed in this initial study of women delivering normal, appropriate-weight-for-age babies. However, women with IUGR had lower concentrations of EGF corresponding to a decreased fetoplacental mass. Although consistently lower concentrations of EGF have been found in subsequent IUGR studies, two recent studies show these to be insufficiently discriminative and variable to be of diagnostic use (Lindqvist et al., 1999).

\section{Leptin}

Leptin regulates body weight and homeostasis and during pregnancy is secreted in increasing amounts with gestational age, from both maternal adipose stores and the placenta (Henson and Castracane, 2000). During pregnancy, there are marked changes in leptin concentrations, which increase sharply during the first trimester and decline back to normal after delivery. It is postulated that the placenta produces these increased concentrations and that circulating leptin provides a growth-promoting signal for fetal development during late pregnancy. Indeed, serum leptin concentrations are significantly lower in new-born babies with IUGR than those in the maternal circulation (Jaquet et al., 1998). Fetal leptin concentrations show good correlation with fetal growth, and leptin concentrations in IUGR fetuses are lower than in controls (Varvarigou et al., 1999), except in cases of severe IUGR in which increased leptin concentrations may be associated with fetal distress (Cetin et al., 2000). In contrast, maternal and placental leptin concentrations are increased in pregnancies associated with IUGR (Lepercq et al., 2001). Umbilical cord leptin concentrations appear to be independent of placental leptin concentrations and hence may be a marker of fat mass in fetuses (Lepercq et al., 2001). It is clear that the site of serum sampling, from either the mother or fetus, is important in determining the diagnostic value of leptin.

\section{Vasoactive peptides}

During pregnancy, extensive haemostatic changes occur in the utero-placental circulation and, in pregnancies complicated by IUGR, a restricted physiological adaptation of the utero-placental blood vessels leads to increased vascular resistance and reduced blood flow. Therefore, candidate markers can be extended to any peptide involved in the control of the utero-placental blood flow and many peptides implicated in causing hypertension are also believed to be responsible for reducing the utero-placental blood circulation. Endothelin (ET-1), a potent vasoconstrictor originally discovered secreted from the endothelium has been implicated in IUGR (Harvey-Wilkes et al., 1996), occurring in increased concentrations in IUGR-associated pregnancy-induced hypertension (Di lorio et al., 1996). However, in ten IUGR pregnancies not complicated by hypertension, decreased concentrations of endothelin were observed (Heffner et al., 1999). Other potential markers include angiotensin II (part of the renin-angiotensin system responsible for controlling blood pressure, electrolyte homeostasis and volume regulation), which occurs in increased concentrations in cases of IUGR (Kingdom et al., 1993), and proinflammatory cytokines such as TNF- $\alpha$, of which there is increased production in cases of IUGR (Holcberg et al., 2001). These factors also enhance the vasoconstriction of the placental bed, thus reducing blood flow. Vasoactive peptides are discussed further in the section on pre-eclampsia. 


\section{Pre-term labour}

The regulatory pathways leading to parturition in humans are not well defined compared with this process in other mammals. As a result, the number of pre-term births has not fallen over the past 30 years, although advances in neonatal care have resulted in a significant increase in successful outcomes. Major economic costs are associated with caring for pre-term neonates and there is epidemiological evidence of increased risk of disease in later life in these individuals (Barker, 1989).

\section{Corticotrophin releasing factor}

Many factors are involved in human parturition, including the interleukins, the endothelins, oxytocin, urocortin and various steroid hormones. Much of the recent and prominent interest in this area has been focussed on corticotrophin releasing factor (CRF), which is released by the placenta during pregnancy in exponentially increasing amounts (Campbell et al., 1987). Until approximately 3 weeks before parturition, the biological activity of this placentally derived peptide is masked by a specific binding protein CRF-BP (Linton et al., 1993; McLean et al., 1995). After this point, the concentrations of CRF exceed those of the CRF-BP, resulting in a sudden increase in the concentrations of bio-available CRF (McLean et al., 1995). It may be this increase that initiates the positive feedback loops that result in parturition (McLean and Smith, 1999).

Many studies have shown that in pregnancies resulting in pre-term birth, the concentrations of CRF in maternal plasma are significantly higher at every stage (Fig. 2a) than those in pregnancies that proceed to full term (McLean et al., 1995). Correspondingly, plasma CRF concentrations are lower in women who deliver post-term. There is some evidence that concentrations of the CRF-BP are correspondingly lower in pre-term than in normal term pregnancies (Hobel et al., 1999). However, these lower concentrations of CRF-BP could be the result of increased clearance of the CRF-CRF-BP complex (Woods et al., 1994), rather than any alteration in the expression of CRF-BP. Although some groups of investigators have reported no differences between normal and pre-term concentrations of CRF, it is generally considered that these findings are the result of interference of the CRF-BP with some CRF assays (Linton et al., 1995). As a result, the concentration of maternal plasma CRF is perhaps the most reliable indicator of patients at risk from pre-term labour. In combination with plasma CRF-BP and alphafetoprotein measurements, such patients can be identified as early as the second trimester (McLean et al., 1999).

\section{Pre-eclampsia}

Pre-eclampsia is a principal cause of maternal morbidity and mortality, and occurs in $3-10 \%$ of pregnancies worldwide. The mild form commonly presents with maternal hypertension and proteinuria, but can swiftly and unpredictably become severe with many extensive complications, involving the maternal liver, kidneys, lungs, blood

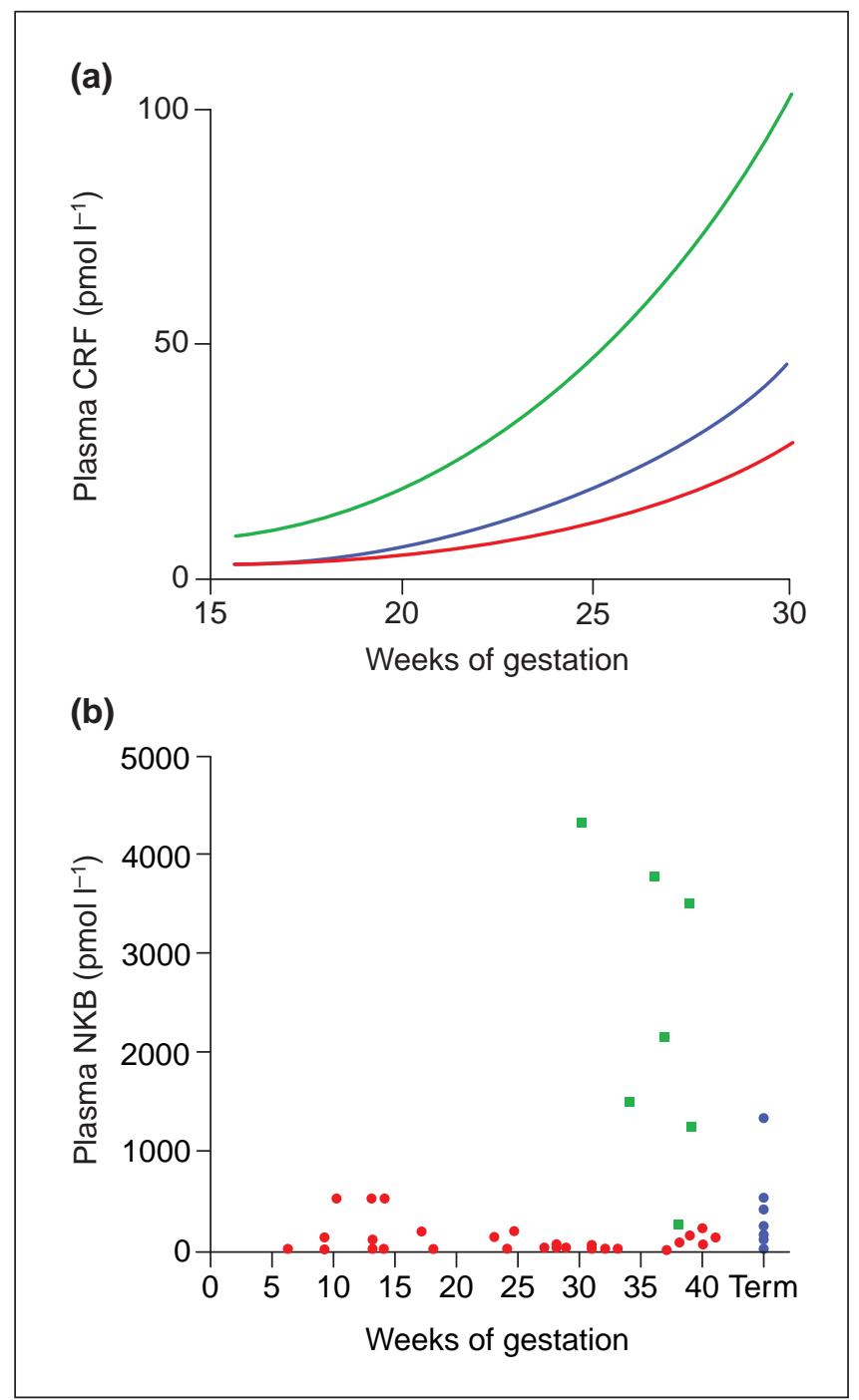

Fig. 2. (a) Regression curves of maternal plasma corticotrophin releasing factor (CRF) versus gestational age for women with spontaneous pre-term labour (green line), spontaneous term labour (blue line) and post-term delivery (red line). (b) Plasma neurokinin $\mathrm{B}(\mathrm{NKB})$ concentrations in normotensive pregnancies (red circles) were determined throughout pregnancy and at term (blue circles). These were compared with concentrations in eight pregnant women with pre-eclampsia in the third trimester (green squares).

vessels and nervous system. These clinical problems only become apparent in the second half of pregnancy but are believed to start during the first trimester. It is thought that defective trophoblastic invasion of the placental bed results in hypoperfusion and an ischaemic placenta, with the release of unknown factors, which pre-date the condition, into the maternal circulation.

\section{Vasoactive peptides}

The most commonly reported symptom in pre-eclampsia is hypertension and it is not surprising that attention has 
focussed predominantly on the powerful vasoconstrictors. In addition, peptides that may be able to compensate for the hypertensive effects of these by regulating the blood flow to the utero-placental unit have received attention. Of the vasoconstrictors, the endothelins and angiotensins, which help control the functions of vascular smooth muscle cells and circulating blood cells, have received most attention. ET-I concentrations are significantly higher in the placental tissues of women with pre-eclampsia (Singh et al., 2001) and, as a consequence, in plasma too (Rust et al., 1997). However, first trimester plasma endothelin concentrations need to be combined with mid-trimester blood pressure readings to increase the predictive value from 55.5 to $68.2 \%$ (Shaarawy and Abdel-Magid, 2000). Similarly, increased concentrations of angiotensin I and decreased concentrations of angiotensin II in the first week after birth are possible indicators of why some women with pre-eclampsia are more prone to deteriorate during this period. (Zunker et al., 1998). Neuropeptide $Y$, an abundant and widespread peptide in the nervous system, is another potent vasoconstrictor that has been implicated in pre-eclampsia. Although increased plasma concentrations of neuropeptide $Y$ have been reported in women with pre-eclampsia (Khatun et al., 2000), other studies have reported no correlation (Egerman et al., 1999). The vasodilators reported as potential markers in pre-eclampsia include atrial natriuretic factor, normally implicated in the control of extracellular fluid volume and electrolyte homeostasis (Zhao, 1993), and vasoactive intestinal polypeptide, normally a neurotransmitter exhibiting a wide variety of biological actions (Holst et al., 1991). Both of these peptides are shown to be higher in women with pre-eclampsia, whereas adrenomedullin, a peptide that elicits long-lasting vasodilation, has been reported both to decrease (Hata et al., 1997) and to increase (Di lorio et al., 1998) in pre-eclampsia in different groups of patients.

Preliminary evidence also indicates that neurokinin B (NKB), previously never found in the periphery, fulfils the criteria for a specific pre-eclampsia marker (Page et al., 2000a). NKB is a member of the tachykinins, peptides that were originally identified as neurotransmitters. NKB has been found to cause the potent contraction of the hepatic portal vein, venoconstriction of the mesenteric beds and the increase in heart rate seen in pre-eclampsia (Page et al., 2000a). NKB is present in high concentrations in the plasma of women with pre-eclampsia and is low or undetectable in most normotensive pregnancies (Fig. 2b) and completely absent in the plasma of men and non-pregnant women (Page et al., 2000a). Placental NKB has several advantages over other candidate markers for pre-eclampsia as it appears unique not only to pre-eclampsia but also to pregnancy, and is not associated with other known hypertensive disorders. NKB secretion may start as early as week 9 of pregnancy as a compensatory mechanism to ensure an adequate blood supply to the fetus. As a result, NKB may be the single most effective predictive marker, detecting women at risk from pre-eclampsia as early as the first trimester.

\section{Non-vasoactive peptides}

Leptin, $\beta$-human chorionic gonadotrophin ( $\beta$-hCG) and inhibin are perhaps the most studied of the non-vasoactive markers for pre-eclampsia.

Maternal plasma leptin increases in gestational hypertension and pre-eclampsia (Vitoratos et al., 2001). Leptin may be predictive of pre-eclampsia, as one study demonstrates the increase of maternal plasma leptin before the clinical onset of pre-eclampsia (Anim-Nyame et al., 2000), although Martinez-Abundis et al. (2000) report that serum leptin concentrations are similar in patients with different grades of pre-eclampsia and normotensive pregnancies.

In the case of $\beta$-hCG, there are several reports of an association with the incidence of pre-eclampsia. hCG is secreted from the blastocyst and early placenta and prolongs the life of the corpus luteum. The detection of hCG secretion is used as the basis for the pregnancy test, the most clear-cut and diagnostic test involving a peptide marker during pregnancy. Vaillant et al. (1996) found hCG concentrations at 17 weeks to be a positive predictor for preeclampsia comparable to the best and earliest testing method for pre-eclampsia, namely the abnormalities of the Doppler waveforms of the uterine arteries. Ashour et al. (1997) found increased concentrations in the second trimester, but this association was only significant among multiparous women. Only when hCG was incorporated into a multifactoral model (including body mass index, parity and age) did the sensitivity of the test prove effective with a specificity of $71 \%$ (Lee et al., 2000).

The inhibins are gonadal glycoproteins that normally regulate pituitary $\mathrm{FSH}$, whereas the related activins are peptides that act as growth and differentiation factors in many cells and tissues. In maternal serum, concentrations of inhibin $A$ are found to be eight times higher and activin $A$ concentrations nine times higher in pre-eclampsia than in controls (Muttukrishna et al., 1997). Very little overlap in inhibin $A$ and activin A concentrations are observed between women with pre-eclampsia and controls, indicating that they both could be very sensitive markers for pre-eclampsia.

\section{Chromosomal disorders}

Another major area in which pre-natal screening is important is chromosomal disorders. Large genomic changes, such as aneuploidy (differences in the number of chromosomes), deletions and other chromosomal rearrangements, have long been associated with pregnancy loss, congenital abnormalities and malignancy. Chromosome disorders are typically the result of errors of recombination at meiosis, and so their occurrence cannot often be predicted before fertilization, although certain risk factors, such as maternal age, might indicate that screening is appropriate. Perhaps the most well known chromosomal disorder is Down syndrome resulting from an extra copy (trisomy) of chromosome 21. Other examples include Patau syndrome (trisomy 13), Edwards syndrome (trisomy 18), Turner syndrome (X0), 
Klinefelter syndrome (XXY), Cri-du-chat syndrome (deleted $5 p)$ and Prader-Willi syndrome (lack of the paternal copy of chromosome 15q).

\section{Serum markers}

It is now common to screen for Down syndrome during pregnancy. The commonly used test is based on a series of serum markers that are increased in affected pregnancies. Although no single marker is sufficient to confirm the condition, a combination of measurements has resulted in a test that can predict Down syndrome with reasonable accuracy, especially if other factors, such as gestational age and maternal weight, are taken into account. Originally, three markers were used: alpha-fetoprotein, hCG and unconjugated oestriol (Wald et al., 1988). Further improvement can be gained by measuring the alpha and beta subunits of hCG separately, and with the addition of inhibinA measurements, the detection rate is raised to $79 \%$ with $5 \%$ false positives (Wald et al., 1996).

However, the markers described above are not specific to trisomy 21, and abnormalities in their concentrations can be indicative of other chromosomal disorders or developmental anomalies. For example, in trisomy 18 and trisomy 13, concentrations of hCG are significantly lower than normal (Brizot et al., 1995) and increased alpha-fetoprotein concentrations (Gremm et al., 1997) are associated with fetal anomalies such as abdominal wall defects, neural tube defects (for example, spina bifida) and other malformations. As a result, additional tests are required to confirm the presence of Down syndrome, or indeed other conditions. Clearly, identification of peptide markers for genetic disorders would be most useful in their diagnosis during gestation, and it is hoped that the approaches discussed elsewhere in this review will yield more suitable markers.

\section{Gestational diabetes}

Between two and five per cent of pregnancies are complicated by diabetes, of which $90 \%$ are classified as gestational diabetes mellitus. Unlike women with type I diabetes, women with gestational diabetes have plenty of insulin. However, the effect of their insulin is partially blocked by a variety of hormones secreted by the placenta, such as oestrogen, cortisol and human placental lactogen. Resistance to insulin usually begins about midway (20-24 weeks) through pregnancy and increases with placental development.

\section{Leptin and growth factors}

One of the major problems gestational diabetes causes is macrosomia. Macrosomia means 'large body' and refers to a baby that is considerably larger than normal. Transport of nutrients such as glucose across the utero-placental unit is unregulated and consequently high glucose concentrations in the maternal plasma result in high fetal plasma concentrations. Since the pancreas of the fetus is normoresponsive, it will produce high concentrations of insulin to modulate this, stimulating cellular uptake of glucose (particularly by adipocytes) resulting in large fat deposits. Consequently, insulin concentrations in cord blood represent a continuum of increasing diabetogenic fetopathy (Weiss et al, 1998). Leptin is increased in infants of both type I diabetic and gestational diabetic mothers (Leperceq et al., 1998; Persson et al., 1999) and women with gestational diabetes have increased plasma leptin concentrations during and after pregnancy (Kautzky-Willer et al., 2001). Furthermore, insulin-related genes such as IGF-I, IGF-II and other growth factors including the FGFs, are expressed in placental tissue and their increased production may contribute to the development of infantile macrosomia. Macrosomia in diabetic pregnancy is associated with high concentrations of maternal IGF-I and IGF-II (Lauszus et al., 2001). FGF-2 is also increased in pregnancies complicated with diabetes. Concentrations in maternal serum, cord serum, and amniotic fluid at term are increased, and the amounts of FGF-2 in maternal serum and cord serum correlate with fetal and placental size (Hill et al., 1995). This FGF-2 may be produced by the syncytiotrophoblast of the placenta (Arnay and Hill, 1998). Thus, maternal FGF-2 may be a useful indicator of both fetal development and maternal pathology (Arnay and Hill, 1998; Hill et al., 1998).

\section{Trophoblastic disease}

Trophoblastic disease includes gestational trophoblastic disease (GTD), a spectrum of rare neoplastic conditions, and gestational trophoblastic tumours (GTTs), the abnormal proliferation of different types of trophoblast. These diseases range from partial hydatidiform moles to choriocarcinomas.

\section{Human chorionic gonadotrophin}

The reported incidence of GTD varies and is an order of magnitude higher in Nigeria than it is in the United States (Elegbe et al., 1984). Although the patterns of hCG secretion are similar in both populations during normal pregnancy, the concentration of the alpha subunit of hCG is persistently higher in Nigerian women than in comparable pregnant American women. The higher concentration of the alpha subunit during pregnancy in Nigeria may be a marker indicating a population of women at higher risk for developing the malignancy (Elegbe et al., 1984). GTTs are always histologically choriocarcinomas and secrete the betasubunit of hCG more abundantly than normal. The serum or urinary concentration of this subunit is found to be proportional to the tumour volume and represents a very good fundamental basis for assessing the need for follow-up treatment for these tumours (Ngan and Wong, 1999).

\section{Other markers}

EGF expression is higher in molar placentas (in which the trophoblast implants normally but exhibits abnormal proliferation) of all gestational ages, linking its role to the proliferative and differentiating activity of the trophoblast. 


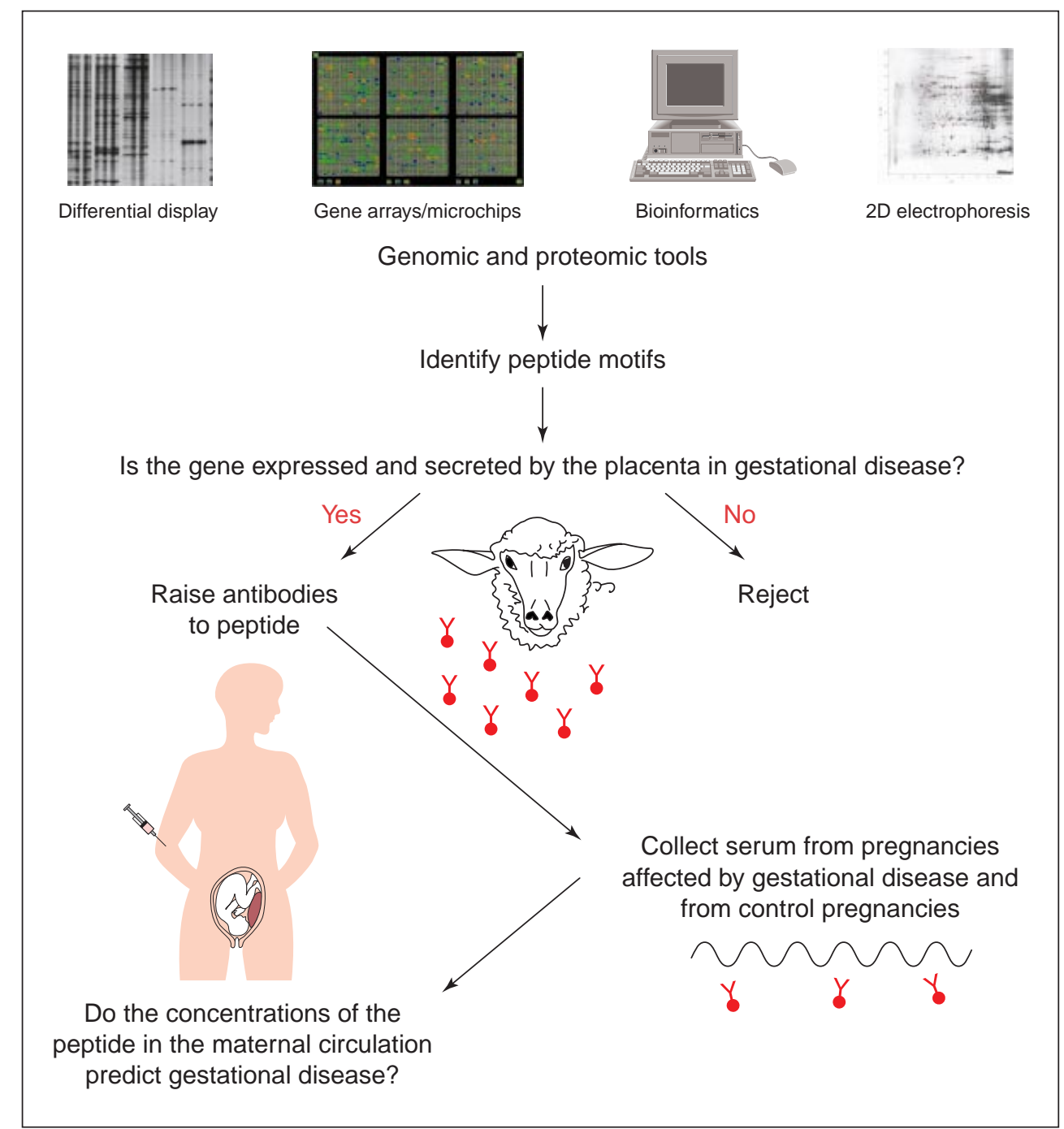

Fig. 3. Discovery of placental peptides plays a key role in the development of any new diagnostic marker. Genomic and proteomic strategies are at the forefront of modern research and in combination represent powerful tools with which to detect novel peptides. Once a new peptide is recognized it is important to determine whether it is differentially expressed in a gestational disease, firstly by looking at gene expression and more importantly by raising antibodies to the peptide, so that the peptide can be screened by a simple blood test.

Tumours resulting in histological diagnosis of invasive moles and choriocarcinomas show very strong binding of EGF and so EGF is believed to have the potential of identifying high-risk lesions (John et al., 1997). Fan et al. (1999) demonstrated that diagnosis of malignant trophoblastic tumours can be made with an accuracy of $91.3 \%$ by detecting early pregnancy factor-like activity, and that this activity could also be used as an indicator to distinguish benign from malignant trophoblastic tumours.

\section{Future discovery of placental peptide markers}

To date, most peptide markers used clinically have been identified using classical approaches such as chromatog- raphy and immunoassay. This is certainly true of the markers of the popular triple test for Down syndrome. Unfortunately, such tests have inherently low accuracies and the need for improvement has led to the inclusion of additional markers. The search for ideal markers in diagnosis and screening continues and as all peptides are encoded by the genome it is possible to use molecular and bio-informatic approaches to trawl the genome for more efficient markers (Fig. 3).

Differential display, which compares and identifies genes expressed at different time points or in different pathologies, can be used to identify new peptides expressed by the placenta (Page et al., 2000b). Although effective in revealing new genes, differential display is time consuming, as the partial gene fragments generated have to be cloned, 
sequenced and reconstructed. Only $7.5 \%$ of the differentially expressed genes we have used encode secreted proteins and hence have any potential as new gestational markers (Page et al., 2000b). Differential display is now being superseded by biochip and microarray systems (for a review, see Jain, 2000), formed either by the synthesis of oligonucleotides or the spotting of DNA fragments onto the surface of glass chips; the latest chips have about a million probe sequences. Hybridization of fluorescently tagged RNA or complementary DNA probes from placentas with different pathologies allows the monitoring of mRNA expression. DNA sequences are identified accurately by a scanning device that detects the fluorescent signals produced by the hybridized probes, and identifies differences in probe binding. Since the sequence of the spotted DNA fragments on the biochips is already known, genes do not have to be cloned and sequenced to obtain additional gene information. The application of proteomics is just as important (for a review, see Palfreyman, 1998). Peptide expression can also be controlled after transcription and important details not observed by differential display may be revealed. Hence, advances in high throughput twodimensional gel electrophoresis and mass spectrometry have added to understanding of the patterns of peptide and protein expression, for example, expression profiles can be attained from extracted placental and serum samples.

Bioinformatics (the integration of biology and computer science) has become one of the fastest growing fields in biological research (for a review, see Luscombe et al., 2001). The momentum of the Human Genome Project has provided the opportunity to gather and store vast arrays of valuable data. These databases can be explored with keywords as simple as 'placenta' or sequence motifs of peptides to identify partial and uncharacterized cDNA sequences such as expressed sequence tags or tentative human consensus sequences (for a review, see Boguski, 1995). 5' and 3' rapid amplification of cDNA ends of candidate placental genes can then be performed to reveal the full-length cDNA sequence of each respective gene. The cDNA can be subsequently translated and analysed by computer programs to reveal and confirm secretory and peptide motifs. The armoury of tools to assist in the identification of new placental peptide precursors and their peptide components has never been greater.

\section{Conclusion}

Many of the tests used currently for gestational disease provide only an estimation of risk and therefore it is vital to develop new prenatal screening tests that are more reliable and specific. A case for early first trimester diagnosis is emerging to help reduce the psychological anxiety and pathological trauma faced by prospective parents. Peptide markers may be able to fill this niche, although ideally they should be unique to the condition and specific to a stage of the disease. It is clear that although peptides are very promising candidates, there remains much to be learnt. Not all peptide markers are unique to any one particular con- dition and there are few large longitudinal studies to guide the use of placental markers in clinics. Consequently, we are left with many reports of different associations of a peptide with a particular disease. Different studies raise, lower or leave unchanged concentrations of a prospective marker, leaving its predictive value questionable. It is perhaps more important to define the root cause of a particular gestational disease. For example, IUGR appears multifactoral, and sometimes the cause might be another gestational disease such as pre-eclampsia. If IUGR occurs concurrently with pre-eclampsia, is it a consequence of preeclampsia or did it arise independently? Should it be markers for IUGR or pre-eclampsia that are chosen? In addition, would the same profile of peptides be expected to be displayed if IUGR arises from maternal diabetes, as opposed to from an infection such as cytomegalovirus?

In conclusion, prenatal screening is an important and routine part of modern obstetric care and the demand for developing new ultimate novel diagnostic markers remains challenging.

The authors would like to thank Sophie Neville, Selma Omer and Nicola Bell for their assistance and help in the preparation of this manuscript.

\section{References}

Key references are identified by asterisks.

Abu-Amero SN, Ali Z, Bennett P, Vaughan JI and Moore GE (1998) Expression of the insulin-like growth factors and their receptors in term placentas: a comparison between normal and IUGR births Molecular Reproduction and Development 49 229-235

Anim-Nyame N, Sooranna SR, Steer PJ and Johnson MR (2000) Longitudinal analysis of maternal plasma leptin concentrations during normal pregnancy and pre-eclampsia Human Reproduction 15 2033-2036

Arnay E and Hill DJ (1998) Fibroblast growth factor-2 and fibroblast growth factor receptor-1 mRNA expression and peptide localization in placenta from normal and diabetic pregnancies Placenta 19 133-142

Ashour AM, Lieberman ES, Haug LE and Repke JT (1997) The value of elevated second-trimester beta-human chorionic gonadotropin in predicting development of pre-eclampsia American Journal of Obstetrics and Gynecology 176 438-442

Barker DJP (1989) Rise and fall of Western diseases Nature 338 371-372

Bocconi L, Mauro F, Maddalena SE, De Iulio C, Tirelli AS, Pace E and Nicolini U (1998) Insulin-like growth factor 1 in controls and growthretarded fetuses Fetal Diagnosis and Therapy 13 192-196

Boguski MS (1995) The turning point in genome research Trends in Biochemical Sciences 20 295-296

Brizot ML, Snijders RJ, Butler J, Bersinger NA and Nicolaides KH (1995) Maternal serum hCG and fetal nuchal translucency thickness for the prediction of fetal trisomies in the first trimester of pregnancy British Journal of Obstetrics and Gynaecology 102 127-132

Campbell EA, Linton EA, Wolfe CD, Scraggs PR, Jones MT and Lowry PJ (1987) Plasma corticotrophin-releasing hormone concentrations during pregnancy and parturition Journal of Clinicial Endocrinology and Metabolism 64 1054-1059

Cetin I, Morpurgo PS, Radaelli T, Taricco E, Cortelazzi D, Bellotti M, Pardi G and Berk-Peccoz P (2000) Fetal plasma leptin concentrations: relationship with different intrauterine growth patterns from 19 weeks to term Pediatric Research 28 646-651

Dalcik H, Yardimoglu M, Vural B, Dalcik C, Filiz S, Gonca S, Kokturk S and Ceylan S (2001) Expression of insulin-like growth factor in the placenta of intrauterine growth-retarded human fetuses Acta Histochemistry 103 195-207 
Di lorio R, Marinoni E, Anceschi MM, Emiliani S, Letizia C and Cosmi EV (1996) Amniotic fluid endothelin-1 levels are increased in pregnancyinduced hypertension and intrauterine growth retardation American Journal of Reproductive Immunology 36 260-263

Di lorio R, Marinoni E, Letizia C, Alo P, Villaccio B and Cosmi EV (1998) Adrenomedullin, a new vasoactive peptide, is increased in preeclampsia Hypertension 32 758-763

Egerman RS, Andersen RN, Manejwala FM and Sibai BM (1999) Neuropeptide $\mathrm{Y}$ and nitrite levels in pre-eclamptic and normotensive gravid women American Journal of Obstetrics and Gynecology 181 921-923

Elegbe RA, Pattillo RA, Hussa RO, Hoffmann RG, Damole IO and Finlayson WE (1984) Alpha subunit and human chorionic gonadotropin in normal pregnancy and gestational trophoblastic disease Obstetrics and Gynecology 63 335-337

Fan X, Yan L, Jia S, Ma A and Qiao C (1999) A study of early pregnancy factor activity in the sera of women with trophoblastic tumor American Journal of Reproduction and Immunology 41 204-208

Giudice LC, de Zegher F, Gargosky SE, Dsupin BA, de las Fuentes L, Crystal RA, Hintz RL and Rosenfeld RG (1995) Insulin-like growth factors and their binding proteins in the term and preterm human fetus and neonate with normal and extremes of intrauterine growth Journal of Clinical Endocrinology and Metabolism 80 1548-1555

Gremm B, Sohn C, Beldermann F and Bastert G (1997) Increased AFP in maternal serum as an indication for invasive diagnosis Zentralbl Gynakol 119 560-566

Harvey-Wilkes KB, Nielsen HC and D'Alton ME (1996) Elevated endothelin levels are associated with increased placental resistance American Journal of Obstetrics and Gynecology 174 1599-1604

Hata T, Miyazaki K and Matsui K (1997) Decreased circulating adrenomedullin in pre-eclampsia Lancet 350 1600-1600

Heffner LJ, Kumari M and Benoit LA (1999) Secretion of the vasoactive peptides, endothelin, and parathyroid hormone-related peptide, by decidual explants from pregnancies complicated by intrauterine growth restriction Journal of the Society for Gynecologic Investigation 6 $273-277$

Henson MC and Castracane VD (2000) Leptin in pregnancy Biology of Reproduction 63 1219-1228

Herbert JM, Basilico C, Goldfarb M, Haub, O and Martin GR (1990) Isolation of cDNAs encoding four mouse FGF family members and characterization of their expression patterns during embryogenesis Developmental Biology 138 454-463

Hill DJ, Tevaarwerk GJ, Caddell C, Arany E, Kilkenny D and Gregory M (1995) Fibroblast growth factor 2 is elevated in term maternal and cord serum and amniotic fluid in pregnancies complicated by diabetes: relationship to fetal and placental size Journal of Clinical Endocrinology and Metabolism 80 2626-2632

*Hill DJ, Petrik J and Arany E (1998) Growth factors and the regulation of fetal growth Diabetes Care 21 (Supplement 2) B60-B69

Hobel CJ, Arora CP and Korst LM (1999) Corticotrophin-releasing hormone and $\mathrm{CRH}$-binding protein. Differences between patients at risk for preterm birth and hypertension Annals of the New York Academy of Science 897 54-65

Hofmann GE, Rao CV, Brown MJ, Murray LF, Schultz GS and Siddiqi TA (1988) Epidermal growth factor in urine of nonpregnant women and pregnant women throughout pregnancy and at delivery Journal of Clinical Endocrinology and Metabolism 66 119-123

Holcberg G, Huleihel M, Sapir O, Katz M, Tsadkin M, Furman B, Mazor M and Myatt L (2001) Increased production of tumor necrosis factor-alpha TNF-alpha by IUGR human placentae European Journal of Obstetrics Gynecology and Reproductive Biology 94 69-72

Holmes RP, Holly JM and Soothill PW (2000) Maternal insulin-like growth factor binding protein-1, body mass index, and fetal growth Archives of Disease in Childhood 82 F113-F117

Holst N, Oian P, Aune B, Jenssen TG and Burhol PG (1991) Increased plasma levels of vasoactive intestinal polypeptide in pre-eclampsia British Journal of Obstetrics and Gynaecology 98 803-806

Jain KK (2000) Applications of biochip and microarray systems in pharmacogenomics Pharmacogenomics 1 289-307
Jaquet D, Leger J, Levy-Marchal C, Oury JF and Czernichow P (1998) Ontogeny of leptin in human fetuses and newborns: effect of intrauterine growth retardation on serum leptin concentrations Journal of Clinical Endocrinology and Metabolism 83 1243-1246

John M, Rajalekshmy TN, Nair MB, Augustine J, Schultz G, Nair MK and Balaram P (1997) Expression of epidermal growth factor in gestational trophoblastic disease (GTD) Journal of Experimental Clinical Cancer Research 16 129-134

Kautzky-Willer A, Pacini G, Tura A, Bieglmayer C, Schneider B, Ludvik B, Prager R and Waldhausl W (2001) Increased plasma leptin in gestational diabetes Diabetologia 44 164-172

Khatun S, Kanayama N, Belayet HM, Bhuiyan AB, Jahan S, Begum A, Kobayashi T and Terao T (2000) Increased concentrations of plasma neuropeptide $\mathrm{Y}$ in patients with eclampsia and pre-eclampsia American Journal of Obstetrics and Gynecology 182 896-900

Kingdom JC, McQueen J, Connell JM and Whittle MJ (1993) Fetal angiotensin II levels and vascular (type I) angiotensin receptors in pregnancies complicated by intrauterine growth retardation British Journal of Obstetrics and Gynaecology 100 476-482

Lassarre C, Hardouin S, Daffos F, Forestier F, Frankenne F and Binoux M (1991) Serum insulin-like growth factors and insulin-like growth factor binding proteins in the human fetus. Relationships with growth in normal subjects and in subjects with intrauterine growth retardation Pediatric Research 29 219-225

Lauszus FF, Klebe JG and Flyvbjerg A (2001) Macrosomia associated with maternal serum insulin-like growth factor-I and -II in diabetic pregnancy Obstetrics and Gynecology 97 734-741

Lee LC, Sheu BC, Shau WY, Liu DM, Lai TJ, Lee YH and Huang SC (2000) Mid-trimester beta-hCG levels incorporated in a multifactorial model for the prediction of severe pre-eclampsia Prenatal Diagnosis 20 $738-743$

Leger J, Noel M, Limal JM and Czernichow P (1996) Growth factors and intrauterine growth retardation II. Serum growth hormone, insulin-like growth factor (IGF) I, and IGF-binding protein 3 levels in children with intrauterine growth retardation compared with normal control subjects: prospective study from birth to two years of age. Study Group of IUGR Pediatric Research 40 101-107

Leperceq J, Cauzac M, lahlou N, Timsit J, Girard J, Auwerx J and Hauguelde Mouzon S (1998) Overexpression of placental leptin in diabetic pregnancy: a critical role for insulin Diabetes 47 847-850

Lepercq J, Challier JC, Guerre-Millo M, Cauzac M, Vidal H and Hauguelde Mouzon S (2001) Prenatal leptin production: evidence that adipose tissue produces leptin Journal of Clinical Endocrinology and Metabolism 86 2409-2413

Lindqvist P, Grennert L and Marsal K (1999) Epidermal growth factor in maternal urine - a predictor of intrauterine growth restriction? Early Human Development 56 143-150

Linton EA, Perkins AV, Woods RJ, Eben F, Wolfe CD, Behan DP, Potter E, Vale WW and Lowry PJ (1993) Corticotropin releasing hormonebinding protein (CRH-BP): plasma levels decrease during the third trimester of normal human pregnancy Journal of Clinicial and Endocrinology Metabolism 76 260-262

Linton EA, Wolfe CD, Behan DP and Lowry PJ (1995) A specific carrier substance for human corticotrophin releasing factor in late gestational maternal plasma which could mask the ACTH-releasing activity Clinical Endocrinology 28 315-324

Liu JP, Baker J, Perkins AS, Robertson EJ and Efstratiadis A (1993) Mice carrying null mutations of the genes encoding insulin-like growth factor I (Igf-1) and type 1 IGF receptor (Igf1r) Cell 75 59-72

Luscombe NM, Greenbaum D and Gerstein M (2001) What is bioinformatics? A proposed definition and overview of the field Methods of Information in Medicine 40 346-358

McCormick MC (1985) The contribution of low birth weight to infant mortality and childhood morbidity New England Journal of Medicine 312 82-90

McLean M and Smith R (1999) Corticotropin-releasing hormone in human pregnancy and parturition Trends in Endocrinology and Metabolism 10 174-178

*McLean M, Bisits A, Davies J, Walters W, Hackshaw A, De Voss K and 
Smith R (1999) Predicting risk of preterm delivery by second-trimester measurement of maternal plasma corticotropin-releasing hormone and alpha-fetoprotein concentrations American Journal of Obstetrics and Gynecology 181 207-215

Martinez-Abundis E, Gonzalez-McLean M, Bisits A, Davies J, Woods R, Lowry P and Smith R (1995) A placental clock controlling the length of human pregnancy Nature Medicine 1 460-463

Muttukrishna S, Knight PG, Groome NP, Redman CW and Ledger WL (1997) Activin A and inhibin A as possible endocrine markers for preeclampsia Lancet 349 1285-1288

Ngan HY and Wong LC (1999) Early detection of persistent trophoblastic tumour by serum human chorionic gonadotrophin monitoring after molar pregnancy Chinese Medical Journal (England) 112 260-263

Ortiz M and Pascoe-Gonzalez S (2000) Serum leptin levels and the severity of pre-eclampsia Archives of Gynecology and Obstetrics 264 71-73

Ostlund E, Bang P, Hagenas L and Fried G (1997) Insulin-like growth factor I in fetal serum obtained by cordocentesis is correlated with intrauterine growth retardation Human Reproduction 12 840-844

*Page NM, Woods RJ, Gardiner SM, Lomthaisong K, Gladwell RT, Butlin DJ, Manyonda IT and Lowry PJ (2000a) Excessive placental secretion of neurokinin B during the third trimester causes pre-eclampsia Nature $\mathbf{4 0 5}$ 797-800

Page N, Butlin D, Manyonda I and Lowry P (2000b) The development of a genetic profile of placental gene expression during the first trimester of pregnancy: a potential tool for identifying novel secreted markers Fetal Diagnosis and Therapy 15 237-245

*Palfreyman MG (1998) Functional genomics conference: from identifying proteins to faster drug discovery Expert Opinion in Investigative Drugs 7 1201-1207

Persson B, Westgren M, Celsi G, Nord E and Ortqvist E (1999) Leptin concentrations in cord blood in normal newborn infants and offspring of diabetic mothers Hormone Metabolism Research 31 467-471

Rust OA, Bofill JA, Zappe DH, Hall JE, Burnett JC, Jr and Martin JN, Jr (1997) The origin of endothelin-1 in patients with severe preeclampsia Obstetrics and Gynecology 89 754-757

Shaarawy M and Abdel-Magid AM (2000) Plasma endothelin-1 and mean arterial pressure in the prediction of pre-eclampsia International Journal of Gynaecology and Obstetrics 68 105-111

Singh HJ, Rahman A, Larmie ET and Nila A (2001) Endothelin-I in fetoplacental tissues from normotensive pregnant women and women with pre-eclampsia Acta Obstetrics Gynecology of Scandinavica 80 99-103
Sorem KA and Siler-Khodr TM (1998) Placental IGF-I in severe intrauterine growth retardation Journal of Maternal and Fetal Medicine 7 1-7

Vaillant P, David E, Constant I, Athmani B, Devulder G, Fievet P, Gondry Boulanger JC, Fardelone P and Fournier A (1996) Validity in nulliparas of increased beta-human chorionic gonadotrophin at mid-term for predicting pregnancy-induced hypertension complicated with proteinuria and intrauterine growth retardation Nephron 72 557-563

Varvarigou A, Mantzoros CS and Beratis NG (1999) Cord blood leptin concentrations in relation to intrauterine growth Clinical Endocrinology (Oxford) 50 177-183

Vitoratos N, Chrystodoulacos G, Kouskouni E, Salamalekis E and Creatsas G (2001) Alterations of maternal and fetal leptin concentrations in hypertensive disorders of pregnancy European Journal of Obstetrics Gynecology and Reproductive Biology 96 59-62

Wald NJ, Cuckle HS, Densem JW, Nanchahal K, Royston P, Chard T, Haddow JE, Knight GJ, Palomaki GE and Canick JA (1988) Materna serum screening for Down's syndrome in early pregnancy British Medical J ournal $297883-887$

*Wald NJ, Densem JW, George L, Muttukrishna K and Knight PG (1996) Prenatal screening for Down's syndrome using inhibin-A as a serum marker Prenatal Diagnosis 16 143-153

Wang HS, Lim J, English J, Irvine L and Chard T (1991) The concentration of insulin-like growth factor-I and insulin-like growth factor-binding protein-1 in human umbilical cord serum at delivery: relation to fetal weight Journal of Endocrinology 129 459-464

Weiss PA, Kainer F and Haas J (1998) Cord blood insulin to assess the quality of treatment in diabetic pregnancies Early Human Development 51 187-195

Woods RJ, Grossman A, Saphier P, Kennedy K, Ur E, Behan D, Potter E, Vale W and Lowry PJ (1994) Association of human corticotropinreleasing hormone to its binding protein in blood may trigger clearance of the complex Journal of Clinicial Endocrinology and Metabolism 78 $73-76$

Zhao SC (1993) The relation between the levels of serum lipid peroxide, superoxide dismutase and atrial natriuretic peptide in placenta, umbilical cord vein and intrauterine growth retardation in pregnancy induced hypertension Zhonghua Fu Chan Ke Za Zhi 28 278-280

Zunker P, Happe S, Louwen F, Evers S and Ringelstein EB (1998) Peripartal temporal course of endothelin 1, angiotensin $\mathrm{II}$, and atrial natriuretic peptide in pre-eclampsia and normotensive pregnancy Fetal Diagnosis and Therapy 13 309-314 